\title{
Lepadarg IIn
}

DATAÇÕES NA BIBLIOGRAFIA ARQUEOLÓGICA BRASILEIRA A PARTIR DOS SÍTIOS TUPI

DATING IN THE BRAZILIAN ARCHAEOLOGICAL BIBLIOGRAPHY ON TUPI SITES 


\title{
Datações na bibliografia arqueológica brasileira a partir dos sítios Tupi ${ }^{1}$
}

\author{
Ângelo Alves Corrêa
}

\begin{abstract}
Resumo: Como recurso heurístico as datações absolutas são indispensáveis para o desenvolvimento de modelos sobre origem e expansão dos povos. Na ausência de um programa sistemático de datações, como no caso dos sítios Tupi, torna-se necessário compulsar a bibliografia para elaborar quadros de datações mais completos. Com o intuito de coletar os dados cronológicos sobre os sítios Tupi um grande número de fontes bibliográficas foi analisado evidenciando que muitas vezes as datações não são publicadas de forma adequada. Destarte, busca-se apresentar aqui os problemas encontrados e as práticas adequadas para dirimi-los. Contudo, apesar dos problemas buscou-se também demonstrar como podem ser promissoras as análises dos dados cronológicos disponíveis na bibliografia. $\mathrm{O}$ estudo dirigido permite considerações sobre os métodos de datações utilizados, o comportamento dos pesquisadores, a distribuição das datas vertical e horizontalmente e modelamentos sobre a expansão dos povos Tupi.
\end{abstract}

Palavras-chave: Arqueologia Tupi; Cronologia Tupi; Datação Rádio Carbono; Datação Termoluminescência.

Abstract: Absolute dating is an indispensable heuristic device to model the origin and expansion of human groups. Lacking a systematic archaeological dating program for Tupi occupation in Brazil, it is necessary to look at the literature to produce an accurate frame. However, a large number of bibliographic sources was analyzed that showed improper publication. We present here some of the problems encountered and their appropriate solutions. Furthermore, we also demonstrate how an analysis of available time series can offer new perspectives. Directed studies allow us to consider the use of dating methods, the researchers' behavior, the vertical and horizontal distribution of dates as well as modelings of the Tupi expansion.

Keywords: Tupi Archaeology; Tupi Chronology; Radiocarbon Dating; Thermoluminescence Dating.

\section{INTRODUÇÃO}

Neste artigo pondera-se como os arqueólogos brasileiros vêm apresentando e trabalhando as datações. Tendo por exemplo a cronologia dos sítios relacionados aos povos Tupi, pretende-se apresentar como se dão os procedimentos de amostragem e extroversão do conhecimento cronológico sobre os povos do passado no Brasil. O uso dos sítios Tupi como exemplo deve-se a existência de um banco de dados que vem sendo constituído há muitos anos (BROCHADO, 1984; NOELLI, 1999-2000; 2004; CORRÊA E SAMIA, 2006; CORRÊA, 2009; 2014; BONOMO ET AL., 2015).

Trata-se aqui não apenas da cronologia dos sítios da tradição Tupiguarani (BROCHADO ET AL., 1969) ou das subtradições Tupinambá e Guarani (BROCHADO, 1984), mas de uma forma mais abrangente dos sítios Tupi, entendidos como aqueles oriundos das atividades destas populações com base na classificação do tronco linguístico Tupi (RODRIGUES, 1984; 2000). Busca-se por este termo evidenciar a possibilidade destes

\footnotetext{
${ }^{1} \mathrm{O}$ texto aqui apresentado é uma adaptação de parte da tese Pindorama de Mboîa e lakare Continuidade e Mudança na Trajetória das Populações Tupi, contemplada com o Prêmio Luiz de Castro Faria/Iphan edição 2015 e com a Menção Honrosa no Prêmio Tese Capes edição 2015.

2 Professor doutor no curso de Arqueologia da Universidade Federal do Piauí (UFPI), Brasil.
} 
sítios serem vestígios deixados por falantes das línguas do tronco Tupi, ao invés de afirmar todos como oriundos das atividades dos falantes de apenas uma das famílias, no caso a Tupi-Guarani.

Com base nesta classificação o quadro de datações adquirido permite duas observações iniciais. Primeiramente, como os pesquisadores tratam os dados cronológicos por meio das publicações, permitindo verificar problemas e sugerir procedimentos. Infelizmente o que prepondera nas publicações não é a melhor das condutas, prejudicando a utilização destes dados por outros pesquisadores e em modelos regionais e gerais. Em segundo lugar, reflete o conhecimento sobre a cronologia dos sítios e possíveis interpretações em termos da história das populações Tupi.

Do total de 643 datas encontradas na bibliografia relacionadas a sítios Tupi só puderam ser utilizadas 618 nos ensaios estatísticos aqui apresentados. Esta redução no universo de datas se deve a problemas na bibliografia que, por ausência de informações básicas ou incongruências, interditam a utilização de muitas destas datas, como veremos adiante. Além disso, muitas datas utilizadas nos ensaios demandaram grande esforço de pesquisa bibliográfica para reunir as informações essenciais aos testes.

As observações e resultados dos ensaios estatísticos apresentados podem ser entendidos como demonstrações das possibilidades de trabalhar com os dados cronológicos disponíveis na bibliografia. Um exemplo recente desta perspectiva é o trabalho de Bonomo et al. (2015), onde os dados cronológicos foram utilizados para modelar uma hipótese de expansão de povos Guarani. Ressalta-se que os resultados aqui alcançados, e referentes a cronologia Tupi, também podem e devem ser perseguidos para outros conjuntos arqueológicos, tais como a cronologia de povos sambaquieiros ou das tradições Aratu, Uru, Una, TaquaraItararé, entre outras.

Os resultados apresentados são fruto de uma ampla pesquisa bibliográfica que exigiu trabalho minucioso e contínuo. A coleta de informações bibliográficas tem caráter infindo, já que além de correções e readequações, é necessária a consciência que novas pesquisas continuarão produzindo dados inéditos. Portanto, enquanto os objetos continuarem em estudo, toda pesquisa bibliográfica é sempre provisória.

\section{TRATAMENTO DOS DADOS}

Por meio do sistema de coordenadas denominado espaço-tempo estabeleceu-se a relação entre datas, cultura material e a história dos povos. Onde o espaço-tridimensional (geográfico) e o tempo são concebidos como indissociáveis para que pontos específicos possam ser considerados eventos. A partir da sincronia latente oriunda da conjunção entre um ponto no espaço geográfico e no tempo, cada sítio arqueológico ou artefato isolado pode ser entendido como um evento. A concatenação de cada um dos eventos espaço-temporais nos permite inferir diacronias e, consequentemente, levando-nos à noção de história. Desta forma, o mapeamento de cada um dos eventos nos permite entender melhor os processos sincrônicos e diacrônicos envolvidos na história das populações. 
Como mencionado anteriormente muitas datações não puderam ser utilizadas devido a forma como foram publicadas. Ressalta-se como principal problema para o uso das datas a negligência dos pesquisadores ao publicá-las. Nas publicações muitas vezes não constam as informações sobre o método de datação (14C, TL, relativo e etc.), o tipo de amostra (se carvão, ossos, conchas, cerâmicas, rochas e etc.), a referência temporal (se a data é $A P, A D$ ou a. C.), desvio standard, se a data foi ou não calibrada, se foi calibrada, qual o programa e versão utilizada (Calib ou Oxcal), se foi utilizada a curva específica para América do Sul (além de sigma, vida média utilizada, reservatório de carbono e etc.) ou mesmo qual o laboratório e ano de medição.

Além disso, a falta de informações contextuais sobre as condições de coleta das amostras trouxe dúvidas quanto a validade e a aplicabilidade das datas adquiridas, como por exemplo, se os carvões teriam sido coletados em estruturas de combustão concentrados ou dispersos pelo perfil estratigráfico, ou mesmo se a coleta se deu por meio de flotação. No caso de sítios multicomponenciais (lítico/Tupi; Uru/Tupi; Aratu/Tupi, sambaqui/Tupi, etc.) fica inviável o uso de datas quando o autor não informa a qual componente as amostras datadas pertencem, ou só informa uma e assume que é válida para toda a história ocupacional do sítio. Também não foram utilizadas nas estatísticas outliers, ou seja, datas destoantes com os contextos regionais, muito recentes ou muito antigas em relação aos demais dados regionais.

Apesar dos desvios temporais oriundos da não calibração das datas 14C, estas não foram calibradas devido às omissões de informações na bibliografia. Como fica claro em Araújo (2001), baseado em Stuiver e Reimer (1998), para calibrar uma data 14C é necessário saber minimamente se a data publicada já foi ou não calibrada, o ano de realização da medição, se foi realizada compensação referente ao hemisfério sul e correções de reservatório de carbono. Tais informações raramente constam nas publicações, inviabilizando o procedimento correto de calibração.

Quanto ao método por termoluminescência ( $T L$ ) apesar de seus resultados não necessitarem de calibração, temos um problema muito semelhante ao de $14 \mathrm{C}$. Pois, para a TL, além de características contextuais de coleta da amostra, deve-se publicar o ano da medição, tendo em vista que, para a data AP (antes do presente) de TL ter referência calêndrica, é necessário subtraí-la do ano da medição, já que o "presente" não é considerado o ano de 1950 como no 14C e sim o ano de medição.

Visando dirimir alguns dos empecilhos gerados pela carência de informações junto às datas publicadas, bem como tornar comparáveis datações relativas e pelos métodos $14 \mathrm{C}$ e TL, foram estabelecidos critérios de contemporização das datas. Estes critérios estão apresentados no Quadro 1, demonstrando como todas as datas foram condicionadas a um mesmo índice de referência utilizando AP para se referir a anos Antes do Presente, considerado o ano de fechamento das análises estatísticas. Ou seja, todas as comparações estatísticas foram realizadas com base na antiguidade da data tomando como referência o ano de $2014^{3}$.

\footnotetext{
${ }^{3}$ As datas como dispostas na bibliografia podem ser consultadas no anexo 01 em Corrêa (2014).
} 
Quadro 01: Critérios de contemporização das datas

\section{Para datas relativas}

-Para datação relativa, apresentada como um intervalo, a data média foi subtraída do ano de 2014. Ex: 1600 a 1700 AD: $2014-1650=364$ AP (data utilizada).

\section{Para datas pelo método do C14}

- Quando na bibliografia a data foi apresentada como AP somou-se 64 para ser relativa a 2014. Ex: 610 AP + $64=674$ AP (data utilizada).

- Quando na bibliografia a data foi apresentada como AD subtraiu-se de 1950 para ser convertida em AP e somou-se 64 para ser relativa a 2014. Ex: $1950-1340 A D=610 A P+64=674$ AP (data utilizada).

\section{Para datas pelo método da Termoluminescência}

- Quando a data estava em AP e o ano da medição foi publicado somou-se a diferença entre 2014 e o ano em que foi realizada a medição. Ex: 640 AP (medido em 1980) + 34 = 674 AP (data utilizada).

- Quando a data estava em AP e o ano da medição não foi publicado considerou-se como sendo o ano 2000, portanto, somou-se 14 a data. Ex: 660 AP (sem data de medição) + 14 = 674 AP (data utilizada).

- Quando estava em AD e foi publicada a data de realização da medição realizou-se a subtração a partir desta para obtenção da data AP e somou-se o número de anos faltantes para 2014. Ex: 1340 AD (medido em 1980): 1980 - 1340 $A D=640 \mathrm{AP}+34=674 \mathrm{AP}$ (data utilizada).

- Quando estava em AD e não foi publicada a data da medição utilizou-se o ano de 2000 como base para subtrair e adquirir a data em AP e somou-se com 14 para ser relativa a 2014. Ex: 1340 AD (sem data da medição): 2000 - 1340 $A D=660 \mathrm{AP}+14=674 \mathrm{AP}$ (data utilizada).

Os dados cronológicos, após sua contemporização, foram utilizados para alimentar planilhas no programa Microsoft Excel ${ }^{\circledR}$ 2013, permitindo a elaboração dos gráficos apresentados, diferindo apenas para o gráfico 3 para o qual foi utilizada a versão trial do programa Corel Draw ${ }^{\circledR}$ X4. Para a elaboração dos mapas de densidade, isócronas e diagrama de fluxo foi utilizada a versão trial do programa $\operatorname{Arcgis}^{\circledR} 10.1$.

\section{CIRCUNSOANTES}

Abre-se parênteses aqui para duas questões que, apesar de indiretamente ligadas com à cronologia das populações Tupi, são fundamentais para um olhar crítico a respeito dos dados cronológicos de um modo geral.

\section{Datações ${ }^{14} \mathrm{C}$ versus TL}

Há uma tendência por parte dos arqueólogos em atribuir maior confiabilidade a datações de Carbono 14 em detrimento das datações por Termoluminescência (SUGUIO, TATUMI E BARRETO, 2003; WATANABE ET AL., 2005; SOARES, 2005). No entanto, não é possível ser tão simplista. Óbvio que a confiabilidade em uma datação depende de uma série de condicionantes, desde como a amostra foi coletada 
e tratada, até a interpretação dos resultados, não havendo, contudo, nenhum motivo prévio para receio quanto às datas de TL. Ao contrário, deve-se tê-las como aliadas no estabelecimento de cronologias.

A primeira característica de excelência de uma data de TL é o fato de ser um método direto, ou seja, data-se o próprio material arqueológico. Enquanto o ${ }^{14} \mathrm{C}$ é na maioria das vezes utilizado de modo indireto, onde atribuímos aos vestígios arqueológicos a data de material orgânico a eles associados. Há uma grande diferença se a data em carbono é oriunda de amostra de restos mortais humanos, de ossos com marcas de uso, de uma estrutura de combustão ou apenas de carvões associados estratigraficamente com estes materiais, sendo essa informação fundamental para atribuirmos maior ou menor confiabilidade a datas de ${ }^{14} \mathrm{C}$. Contudo, a publicação destas informações não é uma prática entre os arqueólogos brasileiros.

Frente às dúvidas sobre a acuidade dos métodos e dispondo do cabedal numérico de centenas de datas para ambos os métodos, realizou-se uma experiência comparativa, aqui demonstrada. Primeiramente a comparação das datas dispostas em um gráfico num total de 430 datas oriundas de $T L$ e ${ }^{14} \mathrm{C}$, das quais 215 de cada um dos métodos como apresentado no gráfico 1. Ressalta-se que as datas não foram escolhidas. Partiu-se de um total de 288 datas de ${ }^{14} \mathrm{C}$ e 316 datas de TL, onde foram eliminadas as datas com valor repetido de $\mathrm{TL}$ e depois as repetidas de ${ }^{14} \mathrm{C}$, tendo em vista que valores iguais seriam sobrepostos, não alterando a curva do gráfico.

Este gráfico demonstra que de forma geral as medidas tomadas por ambos os métodos se comportam de forma semelhante, gerando curvas de período de ocupação muito semelhantes (como as datas de ${ }^{14} \mathrm{C}$ não foram calibradas a diferença entre curvas poderia mudar relativamente). Ainda no gráfico 1, ao aplicar uma função linear, temos as duas linhas de tendência apresentando conformidade entre ambas, reforçando a semelhança no resultado de ambos os métodos.

Outra questão bem interessante a ser observada é a redução do número de datas por volta do século VI (1400 a $1500 \mathrm{AP}$ ) em ambos os métodos, este tipo de anomalia revela certa sincronia apresentada pela quebra em ambas as linhas. 


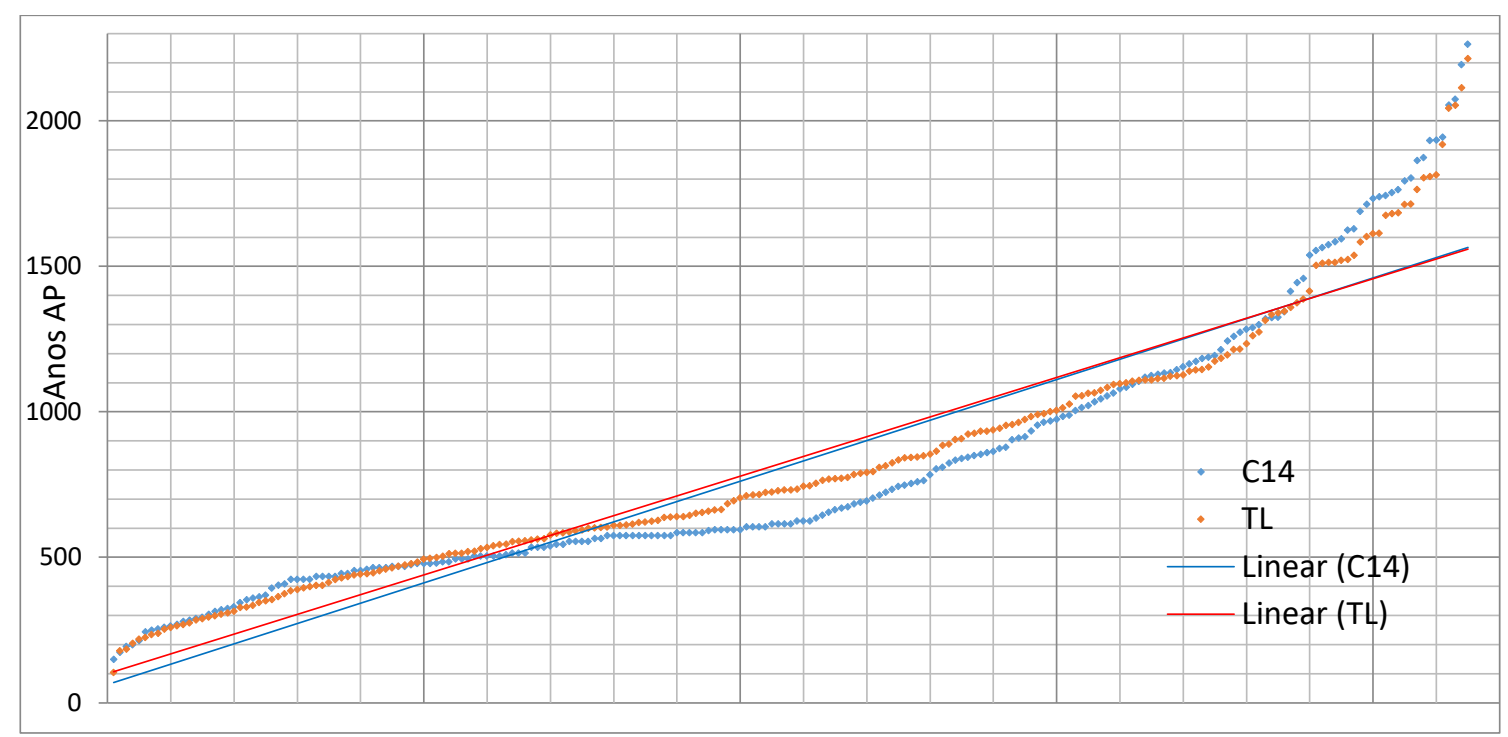

Gráfico 1: Relação entre datações de C14 e TL

Da mesma forma quando dividido o número de datações por séculos temos uma grande semelhança para os dois métodos, evidenciado no gráfico 2 .

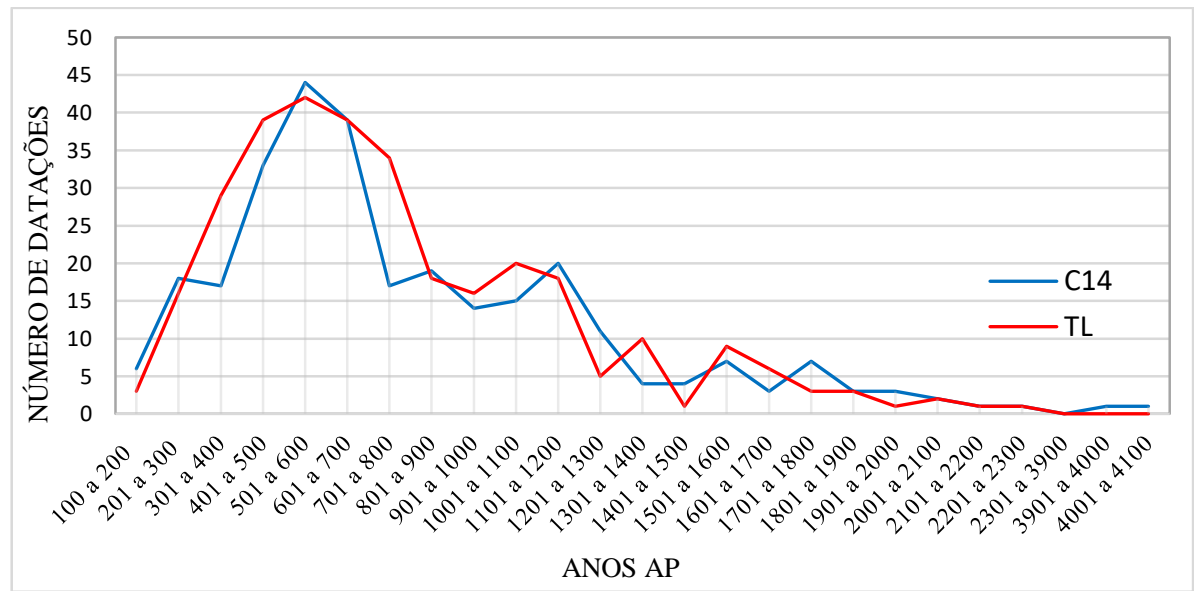

Gráfico 2: Relação entre datações de C14 e TL dividida em períodos

Pelas experiências descritas acima, vemos que no geral os resultados dos métodos de datação são bem concordantes, mas o que acontece se a comparação for específica em um evento? Ou seja, como os dois métodos respondem ao estudo cronológico dentro de um mesmo sítio? O gráfico 3 foi elaborado de modo a permitir comparar os resultados dos dois métodos em sua dimensão relacional. Percebe-se que os resultados de ambos os métodos de datações para um mesmo sítio não são discordantes, nem ocorre preponderância de algum deles com resultados destoantes. 


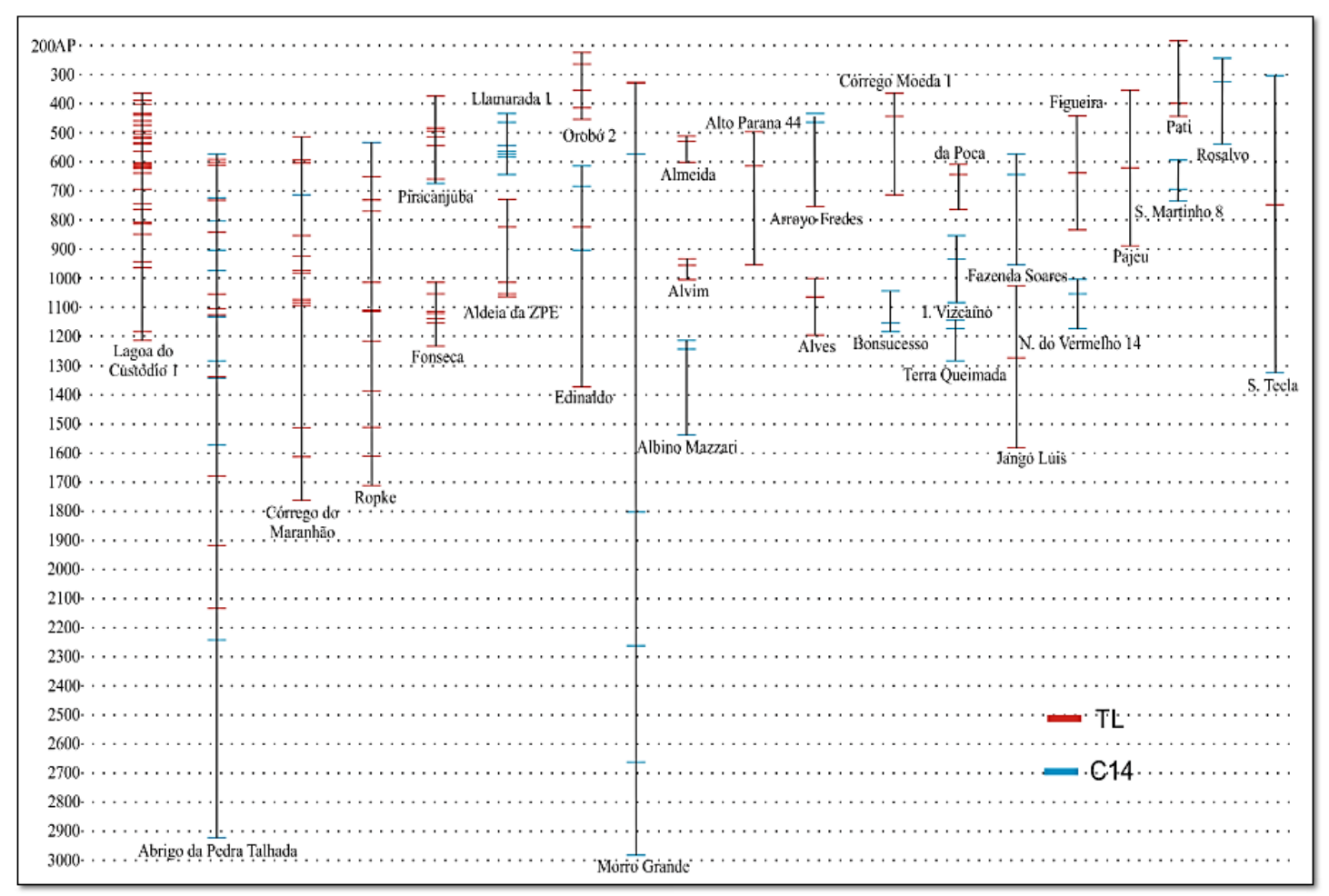

Gráfico 3: Relação entre o número de datações por sítio e período de ocupação

Estes testes reforçam a importância de se utilizar os dois métodos de datação para um mesmo sítio, quando possível. Afinal, para sítios cerâmicos com carvões temos a possibilidade de datar de forma direta e indireta. Quando dispormos de carbono de fonte confiável (tecido humanos, ossos com marcas de uso, estrutura de combustão, etc.), a datação da cerâmica por TL pode reforçar a data de ${ }^{14} \mathrm{C}$, balizar uma calibração ou mesmo se apresentar como crítica ao resultado. Quando o carbono datado não vier de uma fonte confiável, perdurando dúvidas sobre a dimensão relacional entre o carbono e os vestígios humanos (associação amostra-evento), a datação por TL pode ser relevante em dirimir dúvidas ou promover questionamentos.

Datar um evento por mais de um método além de garantir melhor acurácia cronológica, permite melhorias nos próprios métodos por meio de feedback aos laboratórios. Além disso, corretas práticas de escolhas das amostras a serem datadas também são relevantes para os resultados obtidos. A amostragem deve seguir os protocolos dos laboratórios para evitar contaminações e escolhas equivocadas. Uma escolha equivocada de amostras de cerâmicas para realização de TL é não levar em conta as dimensões do fragmento (comprimento, largura, espessura) que, como pré-requisitos, têm limites mínimos, assim como para ${ }^{14} \mathrm{C}$. Um outro equívoco comum é a escolha de cerâmicas com o "coração negro" para realização de TL, pois, em cerâmicas pré-coloniais de queima rápida em fogueira aberta, esta coloração indica que a temperatura não foi suficiente para promover todas as alterações químicas no interior das paredes do vasilhame, inclusive "zerar" a TL (SIMÕES ET AL., 2002). Se esta questão não for levada em consideração na hora da leitura da 
luminescência teremos uma data com considerável erro. Ou seja, assim como para ${ }^{\circ}{ }^{14} \mathrm{C}$, as amostras selecionadas para termoluminescência também dever ser rigorosamente escolhidas e avaliadas quanto a possíveis problemas que não podem ser assacados ao método de datação.

\section{Quantidade versus Precisão}

Por meio do levantamento bibliográfico constatou-se que em $95 \%$ de todos os sítios datados foram realizadas três ou menos datações. Contudo, para alguns poucos sítios foram realizadas várias datações, chegando a dezenas.

A validade de uma única "boa" datação não pode ser desmerecida frente a um maior número de medições feitas em um mesmo sítio. Ou pode-se pensar o contrário, que quanto mais datações forem feitas para um sítio, maior será a precisão quanto ao período de ocupação. São, portanto, duas formas diferentes, mas congruentes, de se encarar a intensidade do investimento em datação para um mesmo sítio.

Contudo, quando se analisa com atenção a cronologia dos sítios com poucas datações em relação aos que possuem muitas, ressaltam-nos duas questões: a) porque os sítios com poucas datações, em sua maioria, apontam para períodos curtos de ocupação? b) porque os sítios com muitas datações, quase sempre, apontam para períodos longos de ocupação?

De forma simplista, pode se arriscar uma indesejável equação onde a extensão do período de ocupação de um sítio fica diretamente proporcional ao número de datações realizadas.

Indesejável por ir contra ao anseio de que o aumento do número de datações melhoraria a precisão em definir o período de ocupação pretérita do local do sítio já que, por maior que fosse o número de medições as datas deveriam incidir em um mesmo intervalo, não se espraiando como podemos ver no gráfico 3.

O gráfico 3 foi construído de forma a expor a dicotomia entre os intervalos de ocupação de todos os sítios com mais de cinco datas (representados pelas onze linhas à esquerda) versus todos os sítios com três datas (as vinte linhas da direita) ${ }^{4}$.

Percebe-se que os sítios com maior número de datações têm intervalos muito maiores que os com menor número de medições, com poucas exceções. Dentro dos dois grupos há algumas exceções, como no caso do sítio Aldeia Tupinambá de Morro Grande que, com cinco datas, ocupa um intervalo de mais de 2500 anos, enquanto o sítio Lagoa do Custódio 1, com 34 datas, se insere no intervalo de aproximadamente 850 anos. Ou ainda, no caso do sítio Santa Tecla que, com apenas três datações, apresenta uma ocupação de mais de 1000 anos. Entretanto, isto não é a regra, o que vemos é a clara oposição entre o lado esquerdo e o direito do gráfico quanto a amplitude do período de ocupação datado.

\footnotetext{
${ }^{4}$ Ressalta-se que só foram utilizadas as datas aceitas pelos próprios pesquisadores, assim as duas datas mais antigas do sítio Ropke não foram expostas, se tivessem sido levariam o sítio até 3500 AP.
} 
Frente a amplitude cronológica alcançadas pelos sítios "extensamente" datados, os pesquisadores esboçam normalmente duas interpretações: a) o sítio é resultante de um longo período de ocupação ininterrupta, sem significativas mudanças na cultura material, ou b) o sítio é resultante de momentos diferentes de ocupação pelo mesmo grupo ou grupos semelhantes, com períodos de abandono evidenciados ou não pela estratigrafia, sem significativas mudanças na cultura material.

Ambas as opções podem ou não refletir a realidade quanto a ocupação do sítio. O problema quanto a estas formas de interpretação é fomentar a desconfiança quanto ao período de ocupação de sítios datados apenas com uma ou poucas datações. Que fique claro que a desconfiança aqui evidenciada não pode pairar sobre um único método de datação, tendo em vista que, no gráfico 3 , ambos os métodos são responsáveis pela amplitude temporal nos sítios.

Mesmo com todas as dificuldades interpretativas vinculadas ao ato de datar eventos passados temos que tentar evitar ao máximo aumentar as possibilidades de erros, contaminações ou dúvidas dos leitores em nossas publicações. Alguns passos devem ser observados para melhorar nossos resultados e sua divulgação:

1 - não descuidar da amostra - coletar uma amostra adequada e tratá-la com os cuidados que cada método necessita são práticas fundamentais;

2 - conhecer os métodos escolhidos - fator essencial para cuidar da amostra e interpretação do resultado;

3 - interpretar o resultado - estudar o resultado da datação é fundamental, seja apenas uma data ou um conjunto, é o pesquisador que atribui valor ao resultado considerando e demonstrando sua validade contextual;

4 - publicar corretamente os resultados - todos os resultados devem ser publicados, mesmo aqueles que não foram considerados válidos, logicamente acompanhados da interpretação. Além disso, há regras para publicar uma data, que nada mais são do que as informações sobre a amostra, o método, referência cronológica, laboratório, dentre outras que estão disponíveis no resultado enviado pelo laboratório ${ }^{5}$.

Cada método de datação e tipo de amostra exige procedimentos específicos, que estão disponíveis na vasta bibliografia sobre o assunto, ou resumidos nas páginas on-line dos principais laboratórios de análise. Uma boa prática é entrar em contato com o laboratório, tomar conhecimento dos procedimentos corretos de coleta e preparação das amostras antes de ir para campo. A interpretação dos resultados não é tão simples e exige do pesquisador conhecimentos sobre os métodos de datação, processo de formação do sítio arqueológico e uso contextual dos artefatos.

\footnotetext{
${ }^{5} \mathrm{O}$ ideal, quando possível, é publicar o laudo do laboratório como anexo, ou na forma de planilha com todas as informações sobre a medida.
} 
Portanto, a questão não é de pessimismo quanto aos métodos, mas de ser crítico em relação às nossas atitudes como pesquisadores, críticos em relação aos laboratórios, e inclusive, conhecer nosso objeto de pesquisa para interpretarmos corretamente os resultados que nos chegam.

\section{DISTRIBUIÇÃO DAS DATAÇÕES}

O grande número de datações reunido na bibliografia é fruto de projetos de pesquisa com diferentes enfoques e objetivos. Portanto, não se deve esperar que tenham uma distribuição equivalente, nem tampouco que representem uma amostragem sistemática de toda a extensão territorial ocupada por povos Tupi. Mesmo sem a equidade desejada, os resultados do cruzamento dos dados cronológicos parecem promissores, desde que se reconheçam os vieses amostrais e os levem em consideração nas interpretações dos resultados.

Em termos amplos, percebe-se o desequilíbrio entre o número de datações disponíveis para sítios associados a povos Tupi nos diferentes países com registro de ocupação, como apresentado na tabela 1 abaixo:

Tabela 1: Distribuição das datações por país

\begin{tabular}{|l|l|l|l|l|l|}
\hline Países & Brasil & Argentina & Uruguai & Bolívia & Paraguai \\
\hline $\begin{array}{l}\text { Número de } \\
\text { Datações }\end{array}$ & 603 & 33 & 4 & 3 & 0 \\
\hline
\end{tabular}

Frente ao grande número de datas elencadas, a primeira medida foi avaliar como a amostragem se distribui verticalmente. Ou seja, como se distribuem as datações ao logo do tempo. Para isso, o universo total de datações foi dividido numericamente em séculos, abarcando de 100 até 4100 AP, como apresentado no gráfico 4 .

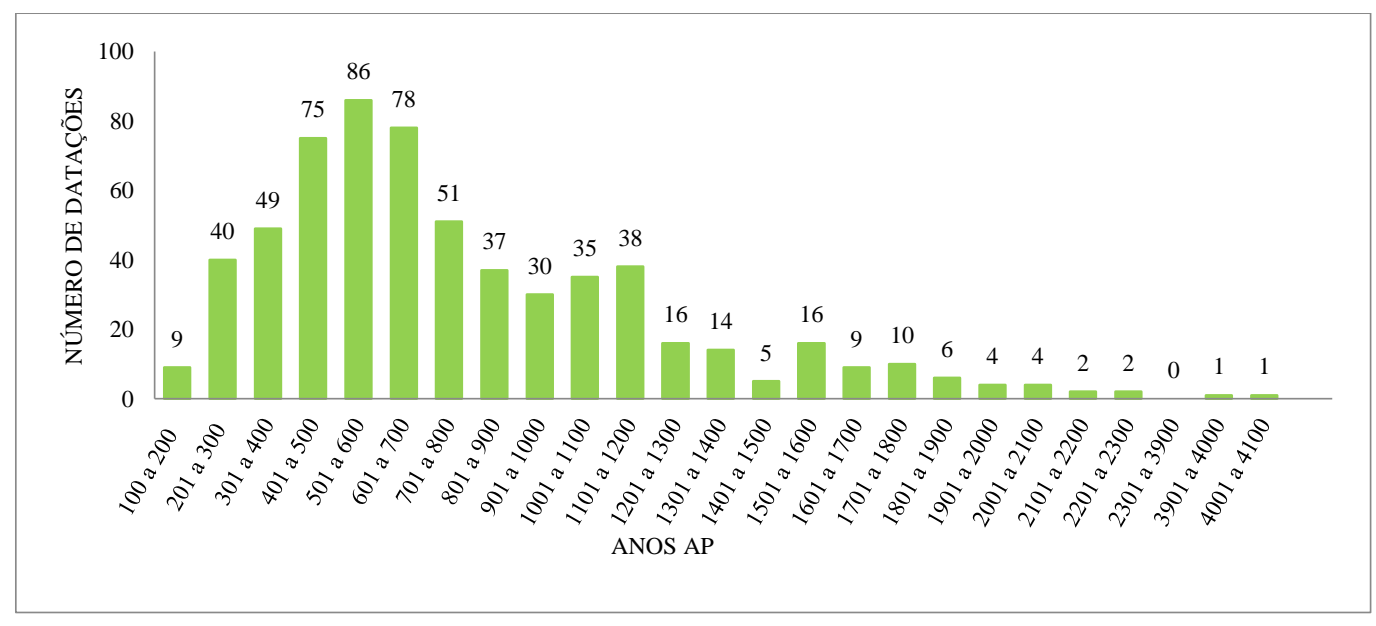

Gráfico 4: Número de datações dividido em períodos AP 
Por meio deste gráfico podemos entender a distribuição do número total de datações ao longo do tempo, e pelo menos dois pontos merecem reflexões. Um destes pontos é a maior ocorrência de datas entre 400 e 700 AP (aprox. séculos XIV, XV e XVI), o outro é o número reduzido de datas para o século VI entre 1400 e 1500 AP.

Sabe-se que alguns pesquisadores, por diversos motivos, acreditavam que as cerâmicas associadas aos Tupi seriam "tardias". Deste modo, quando uma medição apresentava datas antigas, estas não eram publicadas (NOELLI, 2004). Isto provavelmente contribui para presença maior na bibliografia de datas dos períodos mais recentes e anteriores à colonização europeia.

Para além desse problema de escolha em relação ao que se publica, pode-se pensar se não há uma relação entre o número de eventos datados e a densidade populacional para cada século. Por ser leviano fazer uma associação direta, busca-se incitar objeto futuro de pesquisa, questionando se a queda no número de datas entre 1400 e 1500 AP (gráfico 1) seria o reflexo de um menor número de ocupações neste período. Uma resposta positiva seria coerente com uma redução na ocupação pelo menos nas áreas mais pesquisadas até então. De forma análoga, o gradual aumento dos eventos datados entre 700 e 400 AP seria reflexo de um contínuo aumento populacional, levando ao aumento do número de aldeias visíveis como sítios para nós? O pico desse aumento gradual ocorre no século XIV, com queda progressiva associada ao período de invasão e massacre durante a colonização europeia. Outras pesquisas vêm indicando fatores semelhantes na associação entre datações e demografia na Amazônia (MORAES E NEVES, 2012).

Após esta avaliação vertical pode-se considerar a distribuição espacial. Comparando os gráficos 5 e 6 e o mapa 1, percebe-se que as datas mais antigas de cada região estão justamente nos locais com maior número de pesquisas, permitindo considerar um desvio amostral, como já indicado por alguns autores (NOELLI, 2004; CORRÊA e SAMIA, 2006; SCHEEL-YBERT et. al., 2008; CORRÊA, 2009). Este desvio é fruto do descompasso de pesquisas e/ou publicações nas diferentes regiões do país, onde aquelas com maior número de pesquisas e datações tendem a ter as datas mais antigas, ou seja, serem bem conhecidas.

Se não forem ponderados estes desvios amostrais, alguns erros interpretativos podem ser cometidos. Como, por exemplo, considerar as regiões mais amplamente datadas, e por este motivo detentoras de datações mais antigas, como áreas de ocupação recuada ou mesmo como centro de origem das populações pesquisadas (e.g. DIAS, 1995). 
ÂNGELO ALVES CORRÊA

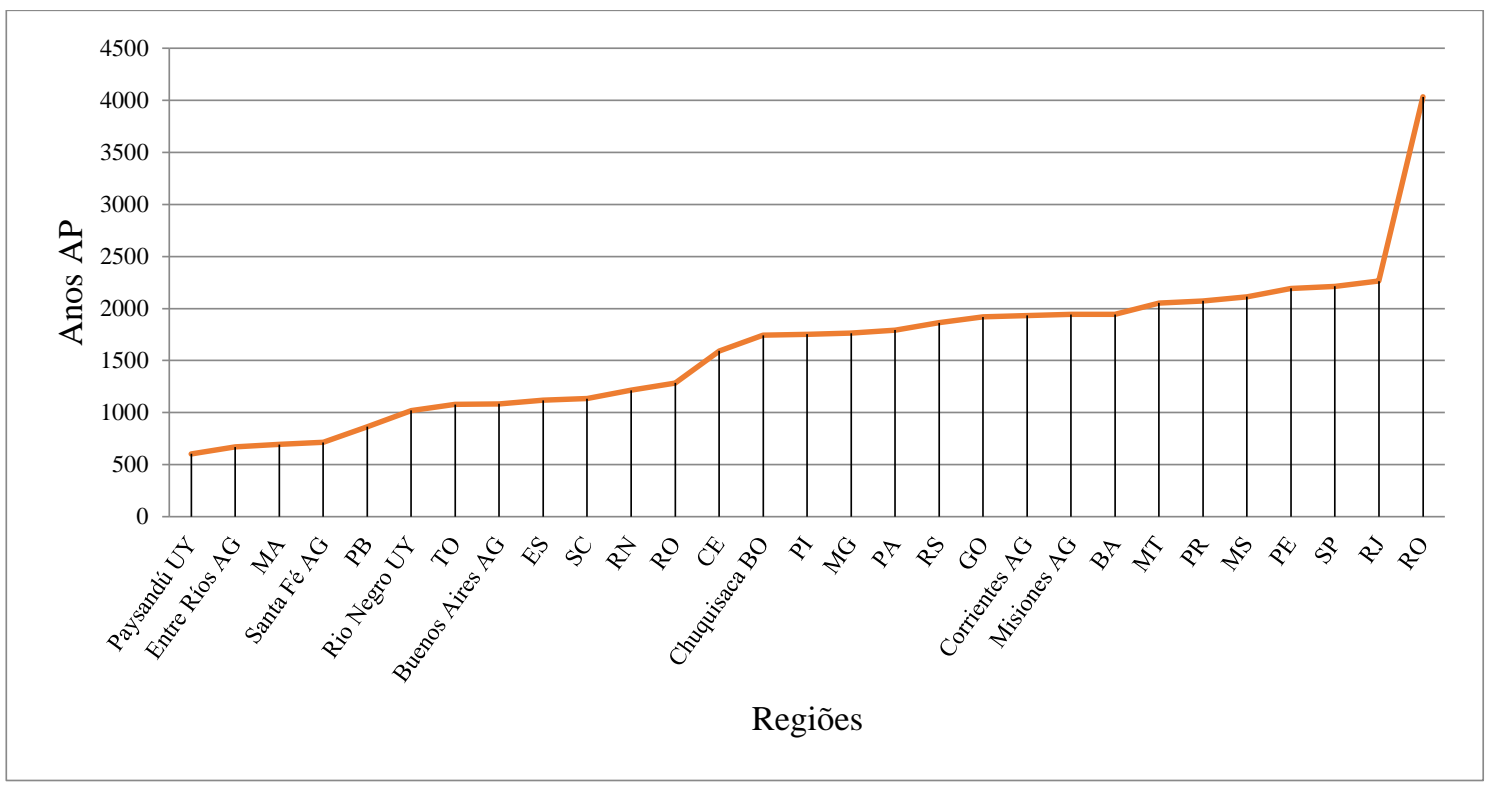

Gráfico 5: Distribuição de datas antigas por região

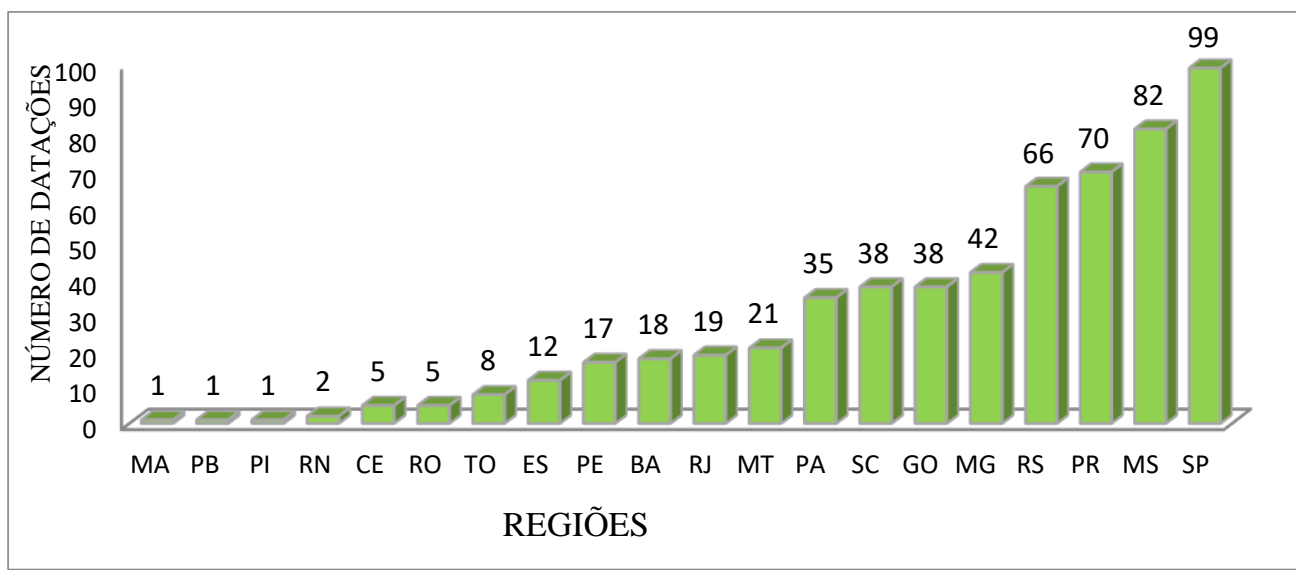

Gráfico 6: Número de datações por estados brasileiros 


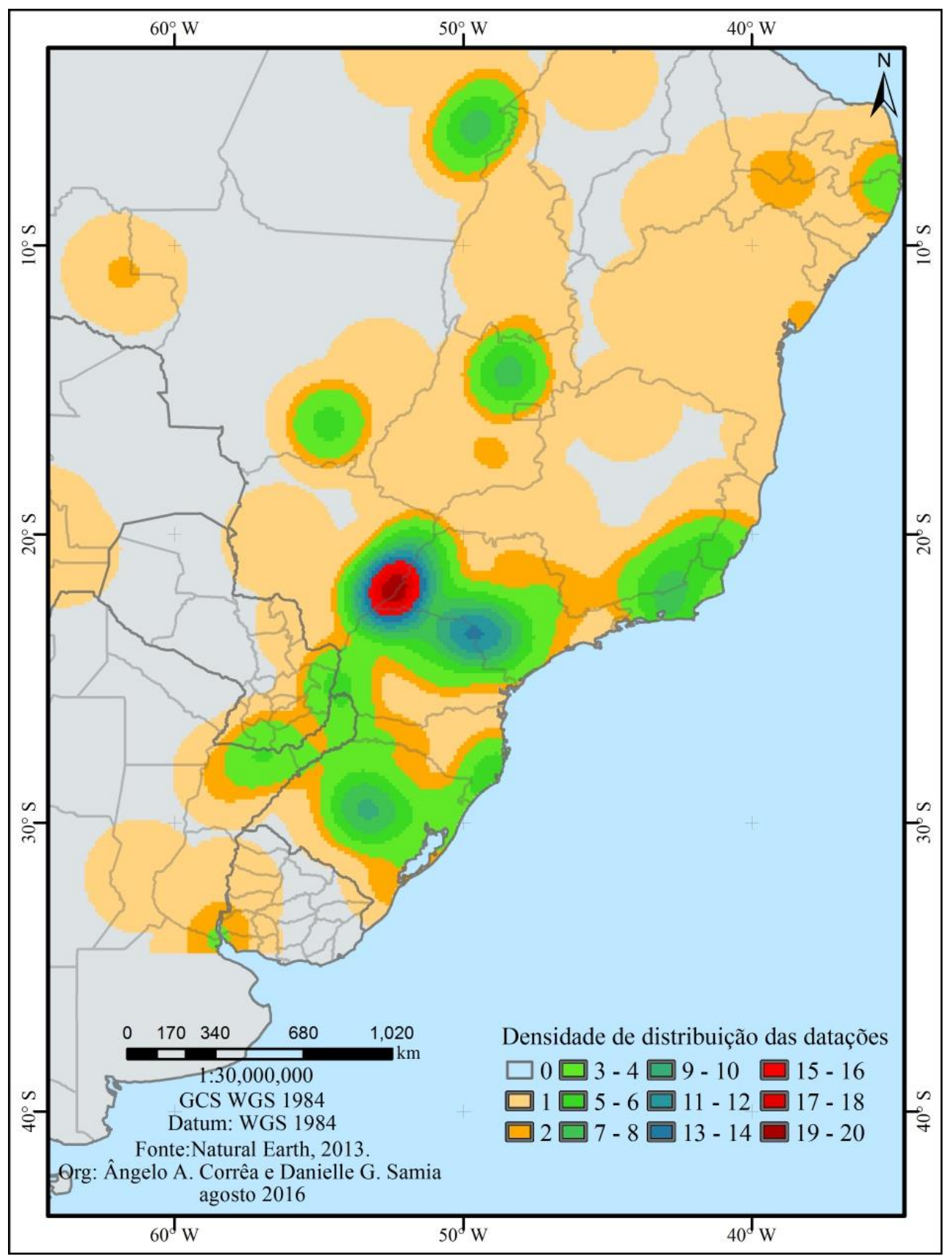

Figura 1 - densidade de distribuição das datações

No gráfico 5, o único desvio da tendência estatística de datas mais antigas serem comuns as áreas mais pesquisadas é o caso do estado de Roraima, provável região de origem dos povos Tupi (RODRIGUES, 1984; 2000). Pois, apesar do levantamento apresentar poucas datas para este estado, é nesta região que estão as datas mais antigas, visto que apresenta profundidade temporal de mais 4 mil anos. As demais datas chegam a 2264 AP (se não for considerada a data de 2920 AP no estado do Rio de Janeiro), configurando um lapso de aproximadamente 1800 anos sem datações relacionadas a sítios Tupi. Este lapso temporal poderia ser sanado com acréscimo de pesquisas nas regiões próximas a Rondônia.

Outra possibilidade para este lapso pode ser a distinção entre sítios associados aos povos de línguas Tupi-Guarani e dos povos Tupi de Rondônia, anteriores a diferenciação da família Tupi-Guarani (ver MELLO 
e KNEIP, 2005; CORRÊA, 2014). Tomando como referência os estudos linguísticos e suas estimativas cronológicas, temos 5000 AP como momento de individualização do Proto-Tupi e 2500 AP para a formação da família Tupi-Guarani (RODRIGUES, 1984; 2000), o que a priori pode ser o que os dados cronológicos expostos no gráfico 5 refletem. Neste gráfico, a data de 4100 AP deve referir-se à ocupação por grupos Tupi não pertencentes à família Tupi-Guarani, enquanto todas as demais datas (mais recentes que 2264 AP) seriam referentes a grupos pertencentes a línguas desta família. Isto se alinha com os resultados das pesquisas realizadas em Rondônia (ZIMPEL, 2009; CRUZ, 2008; MILLER, 2009; ALMEIDA, 2013), que apontam para a significativa diferença entre as cerâmicas encontradas nesta região e aquelas atribuídas aos Tupinambá e Guarani. Assim, as datas mais recuadas devem ser analisadas com cuidado e contextualmente, pois poderiam estar associadas aos falantes de outras famílias linguísticas do tronco Tupi.

\section{DESCOMPASSO - DIFICULDADES DE MODELAMENTOS}

Além do Programa Nacional de Pesquisas Arqueológicas (PRONAPA), não houve no Brasil um outro projeto nacional com metodologias e propostas unificadas. A multiplicação dos centros de pesquisa, o despreparo dos pesquisadores, juntamente com as especificidades da arqueologia têm produzido uma massa de dados muitas vezes ininteligível. A falta de critérios para produção e exposição dos resultados das pesquisas, fruto talvez da própria (des)organização da pós-modernidade, tem produzido uma massa de dados difícil de ser reunida e padronizada para ser utilizada em análises estatísticas extensivas. Os dados coletados permitem demonstrar que não há programas específicos para elaboração de quadros cronológico dentro dos projetos, já que sítios e regiões são datados de forma desigual.

O dado mais óbvio é o descompasso entre o número total de sítios associados aos Tupi e o número de datações. Dos quase 4.900 sítios encontrados na bibliografia, apenas 371 contém todas as 618 datas. Ou seja, apenas $7,4 \%$ dos sítios conhecidos tiveram seus eventos datados. Considerando apenas os sítios datados temos uma média de 1,7 datações feitas por sítio. Na verdade, para a grande maioria dos sítios apenas uma data foi realizada. Como vemos na tabela 2, a maioria dos sítios apresenta de uma a três datas, enquanto uma minoria foi submetida a uma sequência de medições.

Tabela 2: Número de datações por sítios

\begin{tabular}{|l|c|c|c|c|c|c|c|c|c|c|c|}
\hline $\begin{array}{l}\text { № de } \\
\text { Datações }\end{array}$ & 1 & 2 & 3 & 4 & 5 & 7 & 8 & 12 & 14 & 20 & 34 \\
\hline № de Sítios & 262 & 69 & 22 & 6 & 5 & 1 & 2 & 1 & 1 & 1 & 1 \\
\hline
\end{tabular}

Espacialmente também não é boa a resposta amostral dos dados coletados. Temos um total de 197 localidades com datas, onde apenas 10 localidades concentram $30 \%$ de todas as datações, como podemos ver na tabela 3. 
Tabela 3: Número de datações por localidade

\begin{tabular}{|l|c|c|c|c|c|c|c|c|c|c|c|c|c|c|c|}
\hline $\begin{array}{l}\text { No de } \\
\text { Datações }\end{array}$ & 1 & 2 & 3 & 4 & 5 & 6 & 7 & 8 & 9 & 12 & 14 & 15 & 18 & 21 & 46 \\
\hline $\begin{array}{l}\text { No de } \\
\text { Localidades }\end{array}$ & 89 & 41 & 19 & 11 & 8 & 6 & 4 & 3 & 2 & 3 & 2 & 1 & 1 & 1 & 1 \\
\hline
\end{tabular}

A distribuição das localidades com datações também não apresenta coerência amostral com a dispersão de sítios Tupi, havendo concentrações em algumas regiões em detrimento das demais. Este desvio leva a diferenças na densidade do conhecimento sobre a temporalidade de ocupação Tupi em cada porção do território ocupado, como evidenciado no mapa 1.

\section{COMPASSAR - POSSIBILIDADES DE MODELAMENTOS}

Mesmo com todos os problemas e dificuldades na aquisição e uso dos dados cronológicos, de modo algum é possível desprezar as informações disponíveis na bibliografia, pois, como intentado abaixo, é possível por meio de contemporizações utilizar estes dados em ensaios estatísticos, contribuindo com o aperfeiçoamento dos modelos sobre origem e expansão dos povos Tupi.

Os ensaios estatísticos tiveram como foco a espacialização das datas e a demonstração de possibilidades interpretativas. Para isso foram criados mapas com isócronas que permitem atentar para os locais com datas mais antigas ou recentes, além de contar com extrapolações criadas pelos algoritmos de interpolação de dados.

Como existe uma massa de dados cronológicos distribuídos de forma desproporcional vertical e horizontalmente, foram necessários diversos testes para avaliar quais datas pertenceriam à mesma camada de eventos. Entendo por camada de eventos um acontecimento similar que une espacialmente as datas para formar um conjunto quadridimensional, por exemplo, separar as datas mais antigas por região garante força explicativa para indicar o possível momento de colonização de cada região.

O primeiro destes testes foi adicionar as 618 datas e avaliar qual informação obtida. Não houve boa resposta, pois houve a interpolação entre dados recentes e antigos sobrepostos nos mesmos locais, o que levou à necessidade de separar as datas em camadas. Portanto, separou-se as datas mais antigas de cada região e, após vários ensaios com resultados menos legíveis, formatou-se o mapa 2, sendo o resultado mais interessante em relação à distribuição das datas relacionadas aos Tupi aqui cotejadas. Neste ensaio foram utilizadas todas as datas mais antigas para cada região, sem nenhuma data que destoasse com as do entorno, o que levou a uma distribuição mais harmônica e, assim, à possibilidade de percebermos possíveis vetores de deslocamento.

Para este ensaio, duas tendências diferentes podem ser percebidas: a primeira, diretamente relacionada a desvios amostrais onde a região Norte apresenta tendência a datas antigas, e a região Nordeste 
e o estado do Espírito Santo com tendência a apresentar datas recentes. Para estes casos é provável que, futuramente, com a ampliação do número de datações realizadas para estas regiões, o quadro de tendência tenha significativas mudanças, principalmente com relação à região Nordeste.

Já para as regiões Sul e Sudeste, que apresentam as maiores concentrações de sítios com datações, as tendências cronológicas parecem mais concordantes. Para os estados de São Paulo e Rio de Janeiro, temos demarcada uma tendência a datas antigas: pelo menos quatro datações com mais de 2000 AP marcam esta tendência. Contudo, ainda estão isoladas das demais regiões com datas deste período, não sendo possível a definição de isócronas que demarquem vetores.

O oposto pode ser verificado em relação à província de Misiones na Argentina, o noroeste gaúcho e oeste do estado de Santa Catarina, onde há a tendência de datas mais recentes produzindo uma "barreira" entre duas regiões com datas mais antigas (interior do RS e PR). Já o alinhamento de datas mais antigas na província de Corrientes na Argentina, com datas do centro do Rio Grande do Sul, parece confirmar a tendência de chegada dos Guarani a este estado pela região oeste como já sugerido por Brochado (1984; ROGGE, 2004).

Os mesmos dados foram utilizados para a elaboração de um diagrama de fluxo, visando a diagramação automatizada por meio de setas que indicassem vetores dos locais com datas mais antigas para os locais com as datas mais recentes (Mapa 3). Obviamente, o fluxo indicado por cada seta deve ser relativizado de acordo com as incertezas produzidas pela amostragem desigual. Contudo, como ferramenta heurística reflete satisfatoriamente nosso conhecimento, proporcionando base futura para modelamentos automatizados e não automatizados e que contemplem multivariáveis. 


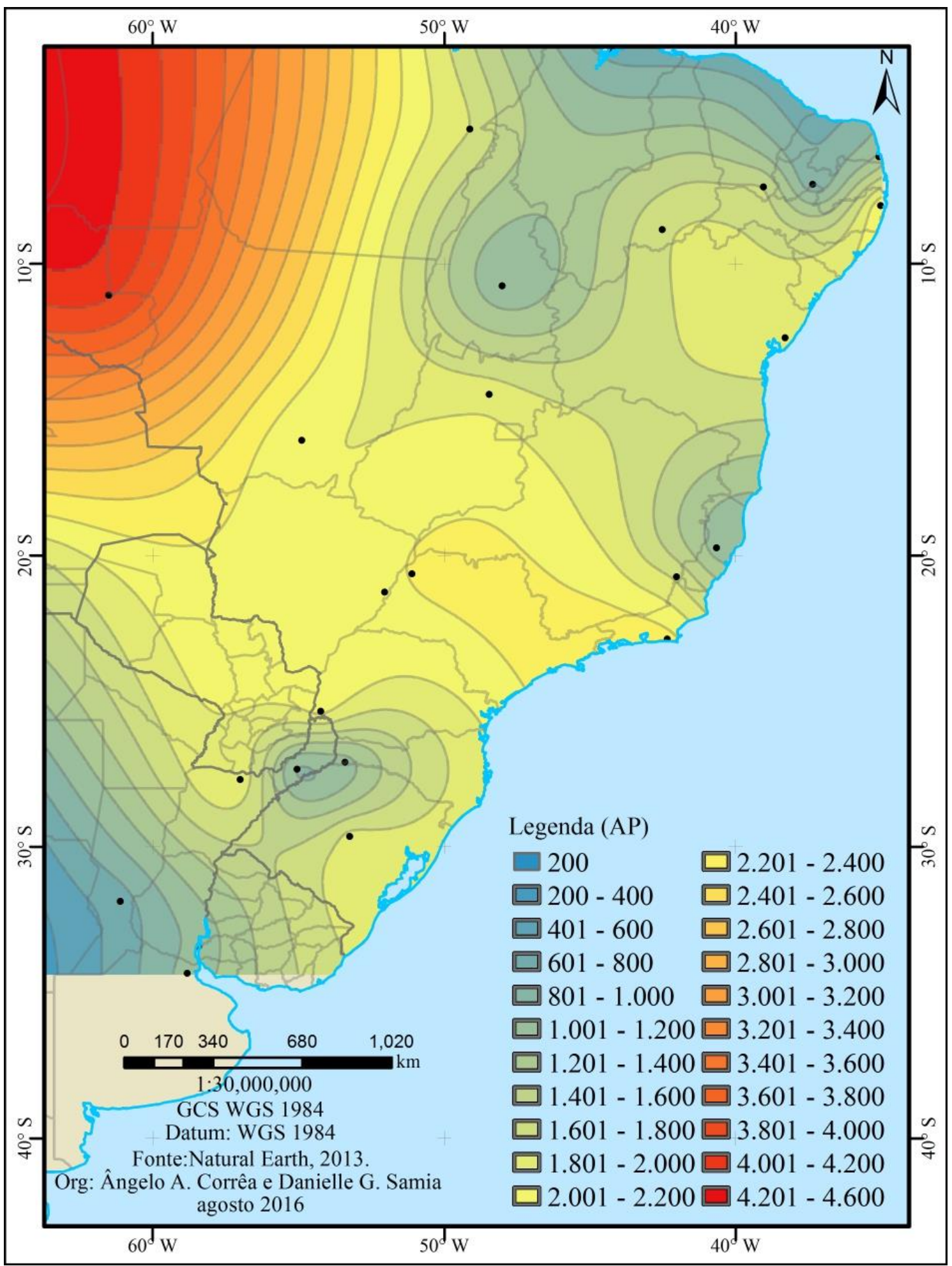

Figura 2: isócronas das datações (AP) mais antigas por região 


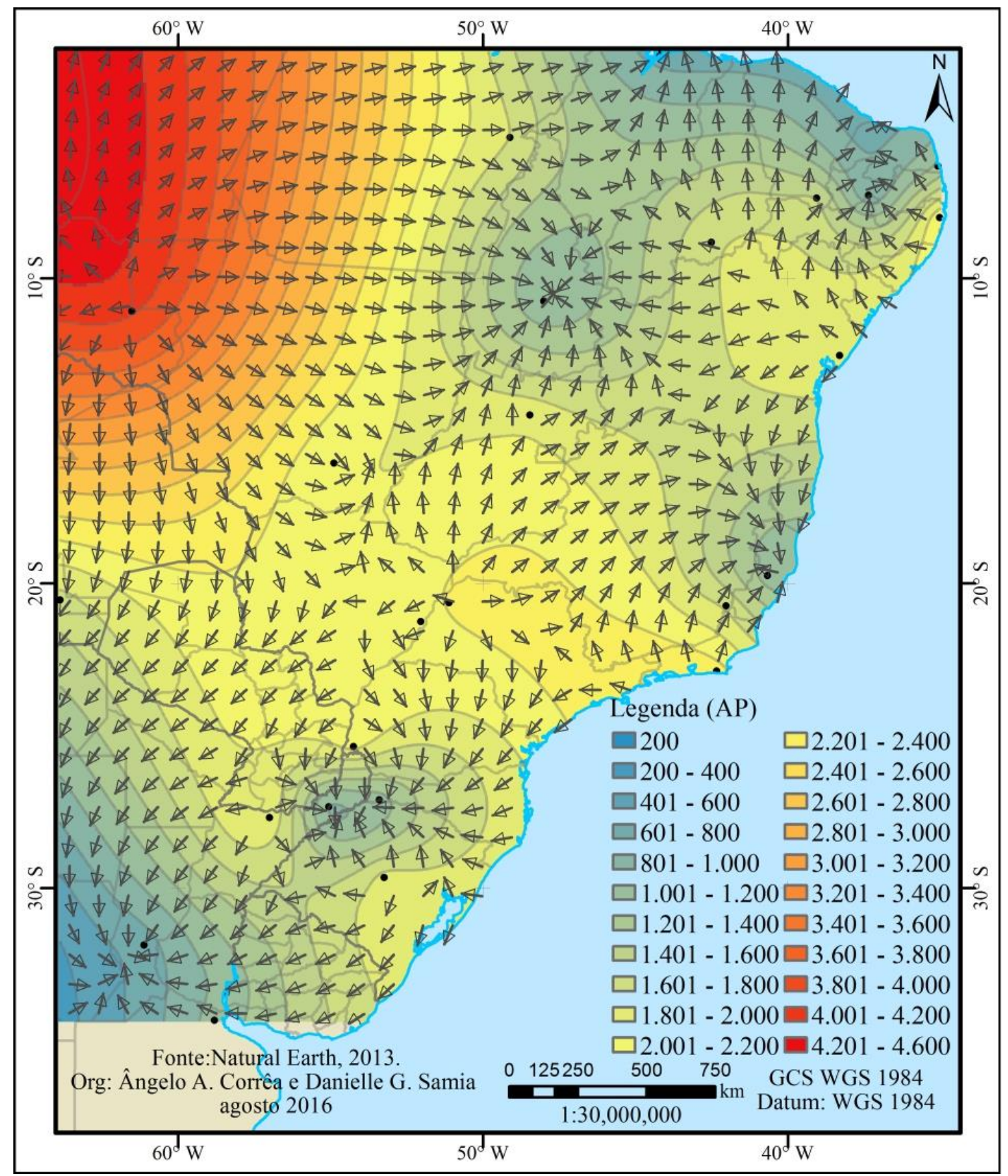

Figura 3: diagrama de fluxo das datações (AP) mais antigas por região

Apesar de ser destoante com as datas regionais, a data de $2920 \pm 70$ AP, a mais antiga do sítio Aldeia Tupinambá de Morro Grande, em Araruama-RJ, foi aplicada visando avaliar o que mudaria no mapa de isócronas se fosse considerada (Mapa 4). Pouca alteração se nota, apenas ficou óbvio um aprofundamento temporal para a região Sudeste. Infelizmente, como esta data está isolada (com esta profundidade só há datas em Rondônia), é difícil que ela possa ser atualmente incluída em modelamentos, pois, neste tipo de comparação, os dados que extrapolem muito uma mediana apresentam comportamento de anomalia. 
Por fim, foram geradas isócronas com as datas mais antigas de cada região sem a data destoante do sítio Aldeia Tupinambá de Morro Grande, utilizando a data de 2200 \pm 70 AP deste sítio, que condiz com as demais datas regionais. Além disso, foram retiradas as datas mais antigas de Rondônia, considerando-se a data $1220 \pm 40$ AP do sítio Terra Queimada (Mapa 5). O objetivo foi avaliar como se comportam as demais datas sem estes dois pontos com datas muito antigas. Com este ensaio temos a exacerbação de alguns outros núcleos com datações antigas. Fica clara a presença de sítios antigos nos estados do Rio de Janeiro e São Paulo e previstas datas antigas entre Mato Grosso do Sul e o Paraguai. Ressalto a presença de duas outras regiões com datas antigas previstas para o estado do Pará e de Pernambuco, que se interligam com as datas antigas da região Sudeste por corredores de fluxo em áreas pouco conhecidas arqueologicamente. Este último ensaio revela o alcance da ferramenta para tratar os dados de regiões específicas tais como estados.

Os mapas de isócronas permitem perceber possíveis "corredores" com valores cronológicos semelhantes. Vemos um corredor seguindo Bolívia, Paraguai, Corrientes, Paraná e Rio Grande do Sul, outro seguindo Pernambuco, Bahia, Minas Gerais, Rio de Janeiro e São Paulo e menos claro pelo interior do Brasil pelo Mato Grosso, Mato Grosso do Sul, Goiás, Minas Gerais, São Paulo e Paraná.

Mais do que pensar nestes corredores como rotas de expansão, os mapas com isócronas apontam quais as tendências que podem ser percebidas com o status atual do conhecimento cronológico relacionado aos Tupi, nos sugerindo não apenas possíveis vetores de movimentação, mas também evidenciando onde pesquisas e datações são necessárias para aperfeiçoar os modelos de expansão destas populações 


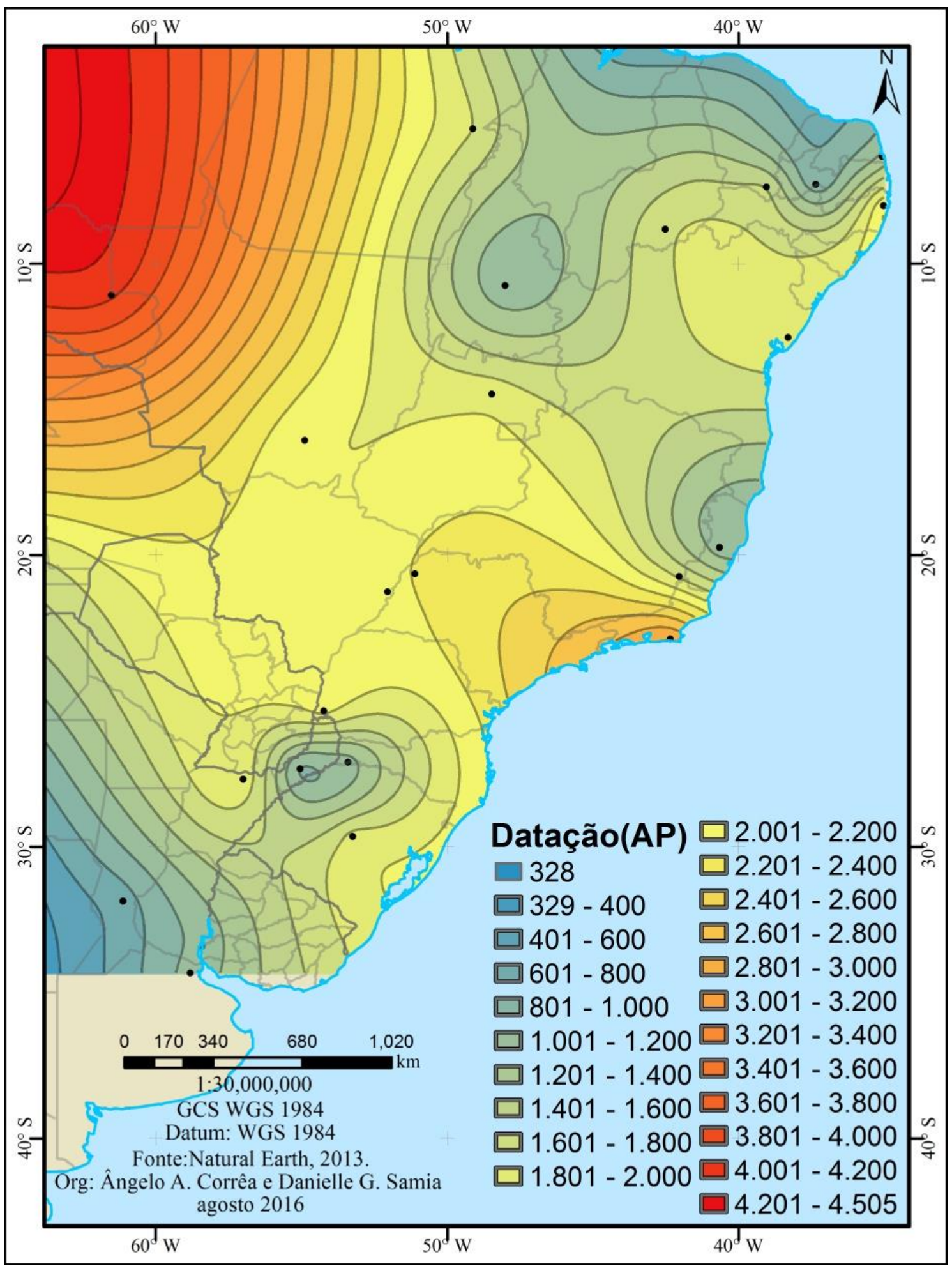

Figura 04: isócronas das datações (AP) mais antigas por região considerando as datas mais antigas de Rondônia e de Araruama (RJ) 


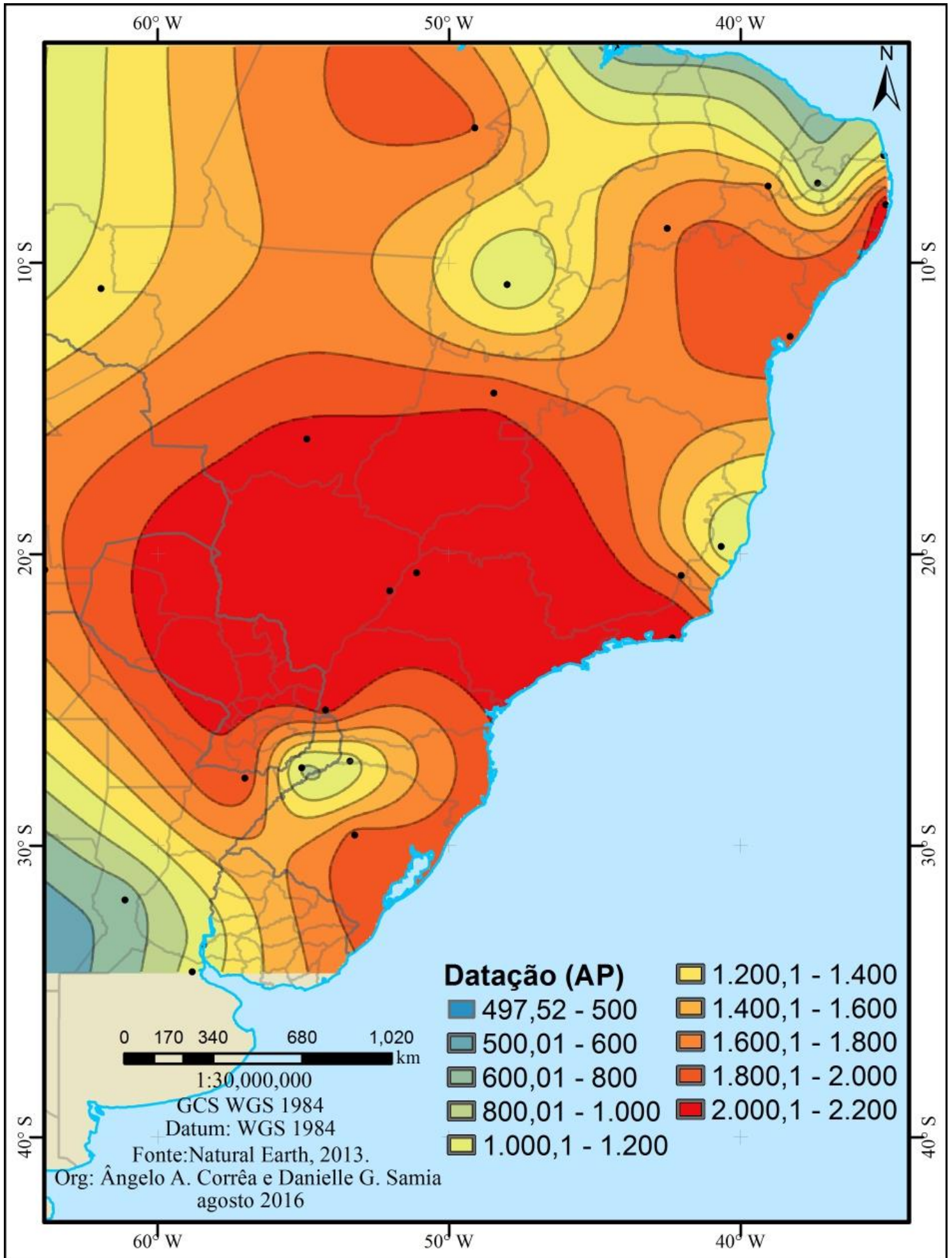

Figura 5: isócronas das datações (AP) mais antigas por região sem considerar as datas mais antigas de Rondônia e de Araruama (RJ)

\section{CONSIDERAÇÕES FINAIS}

Apesar de voltado para a discussão sobre o conhecimento da cronologia dos sítios arqueológicos associados aos povos Tupi, neste artigo foi possível distinguir algumas questões fundamentais para a 
construção de bons quadros de datações relacionados a populações específicas. Ressalta-se que a construção de bons quadros cronológicos depende não apenas de métodos adequados de amostragem e análise, mas também da correta interpretação e publicação dos resultados por parte dos pesquisadores.

A falta de clareza e objetividade como os dados cronológicos atualmente encontram-se na bibliografia, torna os levantamentos bibliográficos mais dispendiosos. Além de interpretações sobre os resultados é pertinente que os pesquisadores publiquem todas as datas conseguidas, mesmo que não sejam condizentes com o esperado, de modo a fomentar outras interpretações. No caso de levantamentos bibliográficos, deve-se explicitar as datas como aparecem nas fontes e deixar claro como foram trabalhadas. Deste modo, garante-se um melhor entendimento das conclusões e permite-se aos demais pesquisadores disporem de compilações.

Além de questões gerais como os cuidados com a coleta de amostras, interpretação e publicação, o exemplo da cronologia dos povos Tupi aponta para a necessidade de estudar o processo de mudança nos conjuntos artefatuais de forma gradativa, ou seja, partindo dos artefatos presentes nos sítios mais recentes até os mais antigos, pois ficou claro que a distinção entre as cerâmicas Tupi-Guarani e as cerâmicas das demais famílias linguísticas pode ser aprimorada se conhecermos as características das cerâmicas etnográficas de cada um destes povos, sendo necessários projetos de pesquisa específicos que visem identificar no registro arqueológico de forma cronologicamente decrescente os vestígios associados aos povos destas outras famílias linguísticas do tronco Tupi (HARDIN e MILLS, 2000).

Como exemplo hipotético, pode-se considerar o estudo em um grupo que ainda produza cerâmica na atualidade, do qual dispomos de cerâmicas produzidas nos últimos 100 anos guardadas em coleções. 0 primeiro passo seria uma análise detalhada das cerâmicas atuais e antigas, para caracterizá-las e dimensionar os processos de continuidade e mudança ao longo dos últimos 100 anos. Além disso, seria necessário identificar por meio dos relatos e documentos etnoistóricos os locais de assentamento deste povo no século XIX e anteriores, submetê-los a escavações (e.g. SILVA E NOELLI, 2015) e estudar os vestígios visando identificar sua relação com os artefatos previamente estudados. Após estudar os sítios com referência etnoistórica, caberia aos arqueólogos detectar sítios que apresentem elementos tecnológicos que permitam sua filiação cada vez mais recuada no tempo, assim, permitindo avaliar como se deu a mudança/continuidade da cultura material neste grupo, fornecendo significativos aportes para o conhecimento dos processos históricos pelos quais passou.

A proposta de uma arqueologia que parte do conhecimento etnoistórico, mais recente para o passado mais profundo ajudaria a resolver problemas de inteligibilidade entre os dados, visto que achar cerâmicas muito antigas em Rondônia não resolveu o problema de como elas estão relacionadas com as cerâmicas associadas aos falantes de línguas Tupi-Guarani (Tupinambá, Guarani, Asurini, Araweté, ou mesmo Kawahíb e Kepkirixát em Rondônia). O mais lógico seria buscar meios que permitam a construção de cronologias que gradativamente recuem no tempo, consorciadas com estudos tecnológicos no que podemos 
chamar de uma Arqueologia Reversa. Para que isto seja possível, dados cronológicos organizados são de fundamental importância. Apesar de simples em conceituação, a Arqueologia Reversa exige muita dedicação dos pesquisadores e longos anos para render frutos. No entanto, é uma forma sistemática e produtiva para estabelecer uma arqueologia como história de longa duração das populações indígenas, permitindo a arqueologia cumprir um papel social frente às comunidades, ao mesmo tempo em que esclarece problemas fundamentais na compreensão dos processos de formação e ocupação do espaço pelos povos indígenas ao longo do tempo.

Numa visão geral, pode-se dizer que pesquisas em arqueologia regional devem contar com adequado levantamento de informações, assim como a elaboração de modelos a partir de dados arqueológicos. Este tipo de levantamento normalmente toma muito tempo nos cronogramas de pesquisa, reduzindo o tempo necessário para a reflexão e produção de novos dados e consequentes avanços no conhecimento. Por este motivo, é de grande relevância a publicação de listas ou bancos de dados completos sobre sítios com base em revisões bibliográficas (e.g. NOELLI, 1999-2000; CORRÊA, 2009; 2014; BONOMO et al. 2015). Na atualidade estes bancos de dados podem ser disponibilizados on-line e contar com atualizações por modelos do tipo input-output, como já vem sendo feito em outras áreas (e.g. www.sp2000.org; www.eol.org), de forma a aproveitar ambientes colaborativos eficientes na plataforma Web, seguindo o conceito de inteligência coletiva (LÉVY, 2003). Como dito, este conceito já é uma realidade utilizada por outras ciências, mas ainda subutilizada pelos arqueólogos, o que dificulta análises como a aqui intentada, ou mesmo sínteses de maior vulto.

\section{Agradecimentos}

Agradeço às dedicadas leituras e sugestões feitas por Fabíola Andréa Silva e Francisco Noelli durante a preparação deste texto para a tese. Agradeço ainda a Francisco Noelli pela disponibilização de seu banco de dados e pela parceria nas pesquisas. Agradeço também a Danielle Gomes Samia pelos mapas aqui apresentados, sem os quais a compreensão seria comprometida. Contudo, o conteúdo e falhas são de inteira responsabilidade do autor. 


\section{REFERÊNCIAS BIBLIOGRÁFICAS}

ALMEIDA, Fernando Ozorio de. A Tradição Polícroma no alto rio Madeira (Tese de Doutorado). Museu de Arqueologia e Etnologia/USP, São Paulo, 2013. Disponível em: http://www.teses.usp.br/teses/disponiveis/71/71131/tde-17072013-140140/. Acesso em: 2015-1228.

ARAÚJO, Astolfo Gomes de Mello. Teoria e Método em Arqueologia Regional: um Estudo de Caso no Alto Paranapanema, Estado de São Paulo (Tese de Doutorado). Museu de Arqueologia e Etnologia/USP, São Paulo, 2001. Disponível em: http://www.teses.usp.br/teses/disponiveis/8/8153/tde-17122013093345/publico/2001_AstolfoGomesDeMelloAraujo_V2.pdf. Acesso em: 2016-06-11.

BONOMO, Mariano; ANGRIZANI, Rodrigo Costa; APOLINAIRE, Eduardo; NOELLI, Francisco Silva. A model for the Guaraní expansion in the La Plata Basin and littoral zone of southern Brazil. Quaternary International, v. 356, p. 54-73, 2015. Doi: http://dx.doi.org/10.1016/j.quaint.2014.10.050

BROCHADO, José. An ecological model of the spread of pottery and agriculture into Eastern South America (Tese de Doutorado). Urbana-Chapaing: University of Illinois, 1984.

BROCHADO, José; CALDERÓN, Valentin; CHMYZ, Igor; DIAS JR, Ondemar; EVANS, Clifford; MARANCA, Silvia; MEGGERS, Betty; MILLER, Eurico; NASSER, Názaro; PEROTA, Celso; PIAZZA, Walter; RAUTH, José; Simões, Mário. Arqueologia brasileira em 1968. Publicações Avulsas do Museu Paraense Emílio Goeldi, 12, 2-39, 1969.

CORRÊA, Ângelo Alves. Tetama nas Matas Mineiras: sítios Tupi na microrregião de Juiz de Fora - MG (Dissertação de mestrado). Museu de Arqueologia e Etnologia/USP, São Paulo, 2009. Disponível em: http://www.teses.usp.br/teses/disponiveis/71/71131/tde-30042009-135816/. Acesso em: 2015-12-28. CORRÊA, Ângelo Alves. Pindorama de mboîa e îakaré: continuidade e mudança na trajetória das populações Tupi (Tese de Doutorado). Museu de Arqueologia e Etnologia/USP, São Paulo, 2014. Disponível em: http://www.teses.usp.br/teses/disponiveis/71/71131/tde-17102014-154640/. Acesso em: 2015-12-28. CORRÊA, Ângelo Alves; SAMIA, Daniele Gomes. Cronologia da Tradição Arqueológica Tupiguarani. In: II Simpósio internacional "A Antiguidade do Homem na América", São Raimundo Nonato. Anais do II Simpósio internacional "A Antiguidade do Homem na América", 2006. Disponível em: http://www.fumdham.org.br/fumdhamentos7/artigos/19\%20Samia\%20Correa.pdf. Acesso em: 2015-12-28.

CRUZ, Daniel Gabriel da. Lar doce lar. Arqueologia Tupi na bacia do Ji-Paraná (RO) (Dissertação de Mestrado). Museu de Arqueologia e Etnologia/USP, São Paulo, 2008. Disponível em: http://www.teses.usp.br/teses/disponiveis/71/71131/tde-06082009-155257/. Acesso em: 2015-1228. 
DIAS, Ondemar. Considerações a respeito dos modelos de difusão da cerâmica a Tupi-guarani no Brasil. Revista de Arqueologia, São Paulo, 8(2), p.113-132, 1995. Disponível em: http://revista.sabnet.com.br/index.php/revista-de-arqueologia/article/view/341/342. Acesso em: 2015-12-28.

EINSTEIN, Albert. A Teoria da Relatividade Especial e Geral. Trad. Carlos Almeida Pereira. Rio de Janeiro: Contraponto Editora Ltda, 1999.

HARDIN, Margaret A.; MILLS, Barbara J. The social and historical context of short-term stylistic replacement: a Zuni case study. Journal of Archaeological and Theory, v. 7, n. 3, p. 139-163, 2000. Disponível em: http://link.springer.com/article/10.1023/A:1026554403077. Acesso em: 2015-12-28.

LÉVY, Pierre. A inteligência coletiva: por uma antropologia do ciberespaço. 4. ed. São Paulo: Loyola, 2003.

MELLO, Antônio Augusto Souza; KNEIP, Andreas. Diálogo Lingüística - Arqueologia: origem e dispersão dos povos Tupi-Guarani. Anais do XIII Congresso da Sociedade de Arqueologia Brasileira, Campo Grande, 2005.

MILLER, Eurico Theofilo. A Cultura Cerâmica do Tronco Tupi no alto Ji-Paraná, Rondônia, Brasil: Algumas Reflexões Teóricas, Hipotéticas e Conclusivas. Revista Brasileira de Linguística Antropológica, 1(1), p. 35-136, 2009. Disponível em: http://periodicos.unb.br/index.php/ling/article/view/7964/6069. Acesso em: 2015-12-28.

MORAES, Claide de Paula; NEVES, Eduardo Góes. O Ano 1000: Adensamento populacional, interação e conflito na Amazônia Central. Amazônica: Revista de Antropologia (Online), v. 4, p. 122-148, 2012. Disponível em: http://periodicos.ufpa.br/index.php/amazonica/article/view/884/1266. Acesso em: 2015-12-28.

NOELLI, Francisco Silva. A ocupação humana na Região Sul do Brasil: arqueologia, debates e perspectivas 1872 - 2000. Revista USP, São Paulo, v. 44, n.2, p. 218-269, 1999-2000. Disponível em: http://www.revistas.usp.br/revusp/article/download/29849/31735. Acesso em: 2015-12-28.

NOELLI, Francisco Silva. La distribución geográfica de las evidencias arqueológicas Guarani. Revista de Índias, vol LXIV, № 230, p. 17-34, 2004. Disponível em: http://revistadeindias.revistas.csic.es/index.php/revistadeindias/article/view/408/476. Acesso em: 2015-12-28.

RODRIGUES, Aryon D. Relações internas na família lingüística Tupí-Guaraní. Revista de Antropologia, p. 3353, 1984. Disponível em:

http://www.jstor.org/stable/41618564?seq=1\#page_scan_tab_contents. Acesso em: 2015-12-28.

RODRIGUES, Aryon D. Hipótese Sobre as Migrações dos Três Subconjuntos Meridionais da Família TupíGuaraní. In: Anais do II Congresso da Associação Nacional de Linguística, XIV Instituto Linguístico, Florianópolis: ABRALIN. 1 CD-Rom, 2000. 
ROGGE, Jairo Henrique. Fenômenos de fronteira: um estudo das situações contato entre os portadores das tradições cerâmicas pré-históricas no Rio Grande do Sul. (Tese de Doutorado). UNISINOS, São Leopoldo, 2004. Disponível em:

http://www.anchietano.unisinos.br/publicacoes/textos/rogge2004/rogge-2004.PDF. Acesso em: 2015-1228.

SCHEEL-YBERT, Rita; MACARIO, Kita; BUARQUE, Angela; ANJOS, Roberto M; BEAUCLAIR, Mariana. A new age to an old site: the earliest Tupiguarani settlement in Rio de Janeiro State? Anais da Academia Brasileira de Ciências, 80(4), p. 763-770, 2008. Disponível em: http://www.scielo.br/pdf/aabc/v80n4/a15v80n4.pdf. Acesso em: 28-12-2015.

SILVA, Fabíola Andréa; NOELLI, Francisco Silva. Mobility and Territorial Occupation of the Asurini Do Xingu, Pará, Brazil: An Archaeology of the Recent Past in the Amazon. Latin American Antiquity, v. 26, n. 4, p. 493-511, 2015. Doi: http://dx.doi.org/10.7183/1045-6635.26.4.493. Acesso em: 11-01-2016.

SIMÕES, Ana Paula Araújo; KUNZLI, Ruth.; MORAES, João Carlos Silos; ARANTES NETO, Moisés de Souza; YUKIMITU, Keizo. Um estudo das temperaturas de queima de cerâmicas e suas consequências na datação arqueológica. Anais do XV Congresso Brasileiro de Engenharia e Ciência dos Materiais. Natal: UFRN, v. único. p. 480-484, 2002. Disponível em: https://www.ipen.br/biblioteca/cd/cbecimat/2002/arqs_pdf/pdf_100/tc101-181.pdf. Acesso em: 2303-2016.

SOARES, André Luis Ramos. Cronologia do Sítio Rs-Jc-57: Problemas e Perspectivas. In: XIII Congresso da Sociedade de Arqueologia Brasileira-SAB, 2005, Campo Grande - MS. Anais do XIII Congresso da Sociedade de Arqueologia Brasileira-SAB - Disco Laser. Campo Grande, MS: Editora Oeste, 2005. Disponível em: http://jararaca.ufsm.br/websites/nep/download/TExtos/ARTV.pdf. Acessado em: 2602-2017.

STUIVER, Minze; REIMER, Paula J. Extended 14C data base and revised CALIB $3.014 \mathrm{C}$ age calibration program. In Stuiver, M., Long, A. and Kra, R. S., eds. Calibration 1993. Radiocarbon 35(1), p. 215-230, 1993.

SUGUIO, Kenitiro; TATUMI, Sônia Hatsue; BARRETO, Alcina Magnólia. Comparação entre os métodos do radiocarbono (14C) e da termoluminescência (TL) na datação do Quaternário. In: Anais do Congresso da ABEQUA, 2003. Disponível em: http://www.abequa.org.br/trabalhos/quatcost_65.pdf. Acessado em: 26-02-2017.

WATANABE, Shigueo; TATUMI, Sônia Hatsue; FARIAS, Thiago Michel de Brito; SOUZA, Suzana de Oliveira; GENNARI, Roseli Fernandes; KUNZLI, Ruth; FARIAS, Deisi Sunderlick Eloy de. Testes de confiabilidade dos métodos de datação por termoluminescência (TL) e luminescência oticamente estimulada (OSL). Revista do Museu de Arqueologia e Etnologia, São Paulo, 15, p. 383-391, 2005. Disponível em: http://www.periodicos.usp.br/revmae/article/view/89744/92556. Acessado em: 26-02-2017. 
ZIMPEL, Carlos Augusto. Na direção das periferias externas da Amazônia: Arqueologia na bacia do rio JiParaná, Rondônia. (Dissertação de Mestrado). Museu de Arqueologia e Etnologia/USP, São Paulo, 2009. Disponível em:

www.teses.usp.br/teses/disponiveis/71/71131/.../MECarlosZimpelNeto.pdf. Acesso em: 28-12-2016. 